Article

\title{
Absolute Configuration of Aliphatic Hydrocarbon Enantiomers Identified by Gas Chromatography: Theorized Application for Isoprenoid Alkanes and the Search of Molecular Biosignatures on Mars
}

\author{
Guillaume Leseigneur ${ }^{1}$ (D), Jean-Jacques Filippi ${ }^{2}$, Nicolas Baldovini ${ }^{1}$ and Uwe Meierhenrich ${ }^{1, *}$ \\ 1 Unité Mixte de Recherche 7272 CNRS, Institut de Chimie de Nice, Université Côte d'Azur, 06108 Nice, France; \\ guillaume.leseigneur@univ-cotedazur.fr (G.L.); nicolas.baldovini@univ-cotedazur.fr (N.B.) \\ 2 Robertet S.A., 37 Avenue Sidi Brahim, 06130 Grasse, France; Jean-Jacques.Filippi@robertet.com \\ * Correspondence: uwe.meierhenrich@univ-cotedazur.fr
}

Citation: Leseigneur, G.; Filippi, J.-J.; Baldovini, N.; Meierhenrich, U.

Absolute Configuration of Aliphatic Hydrocarbon Enantiomers Identified by Gas Chromatography: Theorized Application for Isoprenoid Alkanes and the Search of Molecular Biosignatures on Mars. Symmetry 2022, 14, 326. https://doi.org/ $10.3390 /$ sym 14020326

Academic Editors: Aaron S. Burton and Eve Berger

Received: 17 December 2021

Accepted: 1 February 2022

Published: 5 February 2022

Publisher's Note: MDPI stays neutral with regard to jurisdictional claims in published maps and institutional affiliations.

Copyright: () 2022 by the authors. Licensee MDPI, Basel, Switzerland. This article is an open access article distributed under the terms and conditions of the Creative Commons Attribution (CC BY) license (https:/ / creativecommons.org/licenses/by/ $4.0 /)$.

\begin{abstract}
Acyclic saturated hydrocarbon enantiomers were resolved by gas chromatography using a $\beta$-cyclodextrin-based chiral stationary phase. The stereospecific synthesis of single enantiomers of 4-methyloctane allowed to assign the absolute stereochemical configuration to the resolved enantiomers. Data show that the (S)-4-methyloctane shows higher chromatographic retention as compared to the $(R)-4$-methyloctane due to stronger van der Waals interactions with the $\beta$-cyclodextrin chiral selector. This introductive research presents future prospects for the separation of stereoisomers of larger branched hydrocarbons. We discuss the importance of chiral hydrocarbons, more precisely the stereochemistry of the isoprenoid alkanes pristane and phytane, as potential biosignatures stable on geological timescales. The origins of pristane and phytane in Earth sediments are presented, and we detail the implications for the search of extinct or extant life on Mars. The data presented here will help to systematically investigate the chirality of hydrocarbon enantiomers in biological and nonbiological samples and in samples to be analyzed by the ESA's ExoMars rover to trace the chiral precursors of life in 2023.
\end{abstract}

Keywords: alkanes; chirality; cyclodextrin; ExoMars; gas chromatography; isoprenoids; MOMA

\section{Introduction}

The stereochemistry of chiral alkanes is of significant importance in various scientific fields [1,2]. Chirality and absolute configuration of branched hydrocarbons are, however, often unknown and neglected, because hydrocarbon enantiomers lack functional groups, cannot be derivatized into diastereoisomers and are thereby difficult to resolve, to quantify, and to identify by enantioselective chromatographic and NMR techniques. They also bear no classic chromophores that often are the basis for attributing their absolute configuration. These features lead to very small specific rotations, making absolute configuration assignment of chiral hydrocarbons a formidable analytical challenge [3]. Isoprenoids, a family of branched hydrocarbons, are a broad class of molecules derived from the 5-carbon compound isoprene (2-methyl-1,3-butadiene). Its polymerization can form cyclic compounds and repeating patterns of branched aliphatic carbon chains every four or five carbons (head-to-tail or tail-to-tail linkage, respectively). This often gives rise to multiple stereocenters in the resulting isoprenoid. Isoprenoid hydrocarbons are abundant in biology, often in the form of the hydrophobic side chains of an active molecule with one or several functional groups: this includes the main core membrane lipids of methanogenic and halophilic archaea (archaeol) [4-6], most chlorophylls including those used by algae and cyanobacteria [7] but also tocopherols that are relatively abundant in most photosynthetic organisms (see Figure 1a-c) [8]. 
(a)<smiles>CC(C)CCC[C@@H](C)CCC[C@@H](C)CCC[C@@H](C)CCCC[C@@H](C)CCCOC(CO)CCOCC[C@H](C)CCCC(C)C</smiles>

(b)

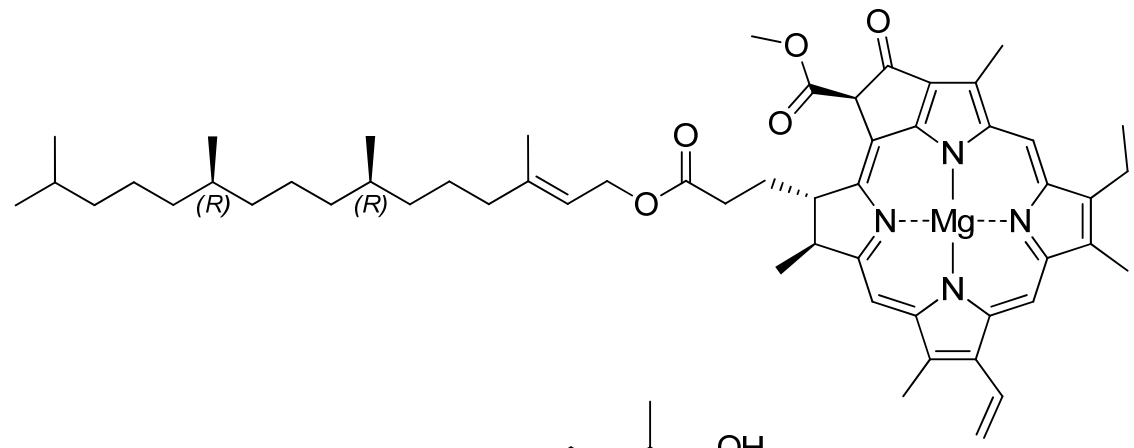

(c)<smiles></smiles>

(d)<smiles>CC(C)CCC[C@H](C)CC(C)(I)C[C@@H](C)CCCC(C)C</smiles>

(e)<smiles>CC[C@H](C)CCC[C@H](C)CCC[C@H](C)CCCC(C)C</smiles>

Figure 1. (a) Archaeol lipid: 2,3-di-O-phytanyl-sn-glycerol, with two phytanyl chains binding to the position of sn-2 and sn-3 of glycerol by ether bonds. (b) Chlorophyll $a$ with its porphyrin ring and phytyl/phytol side chain. (c) $\alpha$ Tocopherol, a type of vitamin E. Note that the stereochemistry of the side chains of these different active biological molecules is the same. (d) Pristane, or 2,6,10,14tetramethylpentadecane derived from $(\mathbf{a}, \mathbf{b}$ or $\mathbf{c})$ becomes $(R, S)$ or meso-pristane due to the absolute configuration notation rules. (e) Biologically derived phytane, or 2,6,10,14-tetramethylhexadecane. The 3rd stereogenic center of phytane is not stereochemically controlled in the case of a chlorophyll origin (shown here). Decomposition of chlorophyll leads to the $R$ and $S$ configuration of this asymmetric carbon in equal proportions.

It is noteworthy that all of these molecules possess a very similar 20-carbon side chain: the archaeal and bacterial phytanyl chains, the unsaturated phytyl moiety of chlorophylls, and the saturated one of tocopherols (leading to an additional stereogenic center). It is even more remarkable that they exclusively appear enantiomerically pure in biology, where the $R$ configuration of carbons atoms 3,7 , and 11 in the phytanyl chains of archaeol is identical to that of the corresponding asymmetric centers in tocopherols, and that carbon atoms 7 and 11 show the same configuration as the corresponding ones in the phytol/phytyl side chain of chlorophylls [9]. This homochiral presence has often been neglected in comparison to the homochiral occurrence of L-amino acid and D-ribofuranose units in proteins and nucleic acids, respectively [10]. While these would undoubtedly be the best evidence of recent Earth-like or extant life if found on Mars, they racemize and degrade very quickly on a geological timescale [11,12], making them less useful for the search of extinct ancient life, which is argued to be the most likely scenario if life ever started on Mars [13]. This is where the stability of isoprenoid alkanes is extremely useful.

The diagenesis of the discussed lipids, chlorophylls, and tocopherols ultimately lead to a majority of pristane (Figure 1d) and phytane (Figure 1e) [14,15]. These C19 (pristane) and C20 (phytane) isoprenoid alkanes tend to dominate the branched and cyclic alkane 
fractions of petroleum and sedimentary rock extracts [16]. They inherit the stereochemistry from their natural precursors, and due to their stability have been shown to keep that information over geological timescales, even at great depth under high temperatures and pressures [17-20].

In 2023, the ESA's ExoMars mission plans to deliver the Rosalind Franklin rover on the surface of Mars [13]. This rover is equipped with the Mars Organic Molecule Analyser (MOMA) [21], a gas chromatograph containing (among three other columns) the enantioselective CP Chirasil-Dex CB capillary column from Agilent, using the same $\beta$-cyclodextrin chiral stationary phase that was used for this research. The MOMA instrument will be used to resolve and quantify organic molecules including enantiomers in surface and subsurface (up to a depth of $2 \mathrm{~m}$ ) samples of Mars [22,23]. The results presented here prepare for the chirality experiment onboard the ExoMars mission that is capable not only to search for the chirality of amino acids and sugar molecules, but as described here also hydrocarbon enantiomers to distinguish their biological versus nonbiological origin.

The reasoning that isoprenoids are some of the best candidates for signs of extinct life is, of course, not a new insight and has been talked about [24] and explicitly stated by the MOMA science team [21], as well as the fact that the focus of ExoMars is on signs of ancient life.

However, the use of the stereochemistry of these isoprenoid alkanes, while it has been a growing tool for the maturation and quality analysis of different sediments [25-27] and crude oils $[17,28,29]$, has not yet been mentioned for Martian surface and subsurface analysis.

This research brings forward the importance of characterizing the resolution power of $\beta$-cyclodextrin capillary columns on a range of simple branched hydrocarbon enantiomers but also on the bigger isoprenoid alkanes relevant for the search of biosignature on Mars. For the latter, the resolution is made easier by the fact that, as pointed out on Figure 1, pristane and phytane coming from the diagenesis of biological molecules are diastereoisomers of their abiological counterparts and are therefore separable on non-chiral capillary columns. Although cyclodextrin-based chiral phases have been shown to produce higher separation on diastereoisomers as well $[30,31]$, they have been resolved only by achiral columns so far in petroleum geochemistry.

First experimental attempts to resolve hydrocarbon enantiomers by enantioselective gas chromatography (GC) using $\beta$ - and $\gamma$ cyclodextrins as well as Chirasil-Val stationary phases explicitly failed [32]. These experiments were performed in preparation of the ESA's cometary Rosetta mission [33] with the aim to resolve enantiomers of different families of chiral organic molecules. In 2001, the application of the enantioselective Chirasil-Dex CB phase using permethylated $\beta$-cyclodextrin allowed for the resolution of rac-3-methylheptane and its higher homologs with a resolution of $0.40<\mathrm{Rs}<0.68$ [34]. Rac-3-Methylhexane had been separated first on a $50 \mathrm{~m} \gamma$-cyclodextrin phase [35]. In 2003, the systematic enantiomeric resolution of branched chiral hydrocarbons required the injection of liquid nitrogen directly into the GC oven, allowing for the baseline separation of rac-3-methylhexane and rac-4-methyloctane enantiomers. The absolute configuration of the chromatographically resolved hydrocarbon enantiomers has remained unknown $[1,36]$.

\section{Materials and Methods}

$(R)$ - and (S)-4-methyloctane were prepared by a known two-step procedure [37] based on the reaction of dibutylcuprate(I) with $(S)$ - and (R)-2-pentyl tosylates, synthesized from the corresponding commercial enantiopure pentan-2-ols (Figure 2).

Enantioseparations of $(R)_{-},(S)-$, and rac-4-methyloctane were performed using an Agilent 6890N-5973N GC-MS system (Agilent, Santa-Clara CA, USA) equipped with a Varian Chrompack Chirasil-Dex CB capillary column ( $25 \mathrm{~m} \times 0.25 \mathrm{~mm} ; 0.25 \mu \mathrm{m}$-thick film). The three compounds were analyzed following the same exact protocol.

The injected sample was a solution of $0.5 \mathrm{~g} / \mathrm{L}$ concentration of the analyte in pentane. The injection volume was $1 \mu \mathrm{L}$ with a split ratio of 100:1. The flow rate was a constant $1.0 \mathrm{~mL} / \mathrm{min}$ of $\mathrm{He}(99.9995 \%)$ carrier gas. The injector temperature and the MS transfer- 
line were set at a constant $230{ }^{\circ} \mathrm{C}$ and $200{ }^{\circ} \mathrm{C}$, respectively. The oven temperature was programmed for $3 \mathrm{~min}$ at $30^{\circ} \mathrm{C}$ then ramped to $50{ }^{\circ} \mathrm{C}$ by $1{ }^{\circ} \mathrm{C} / \mathrm{min}$ ( $5 \mathrm{~min}$ final isotherm). After a solvent delay of $5 \mathrm{~min}$, ions were detected within a $35-350 \mathrm{~m} / \mathrm{z}$ range.

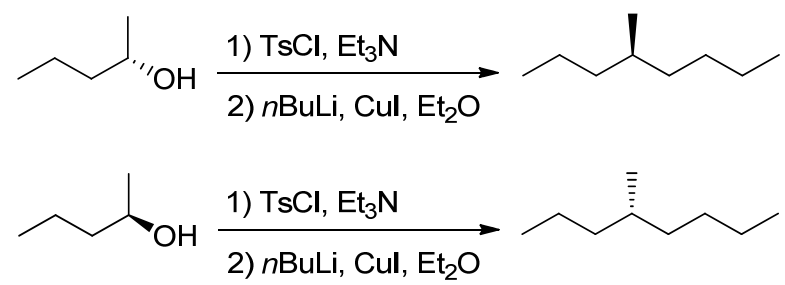

Figure 2. Synthesis of 4-methyloctane enantiomers using the corresponding enantiopure pentan-2-ols as reactants.

\section{Results}

We present the gas chromatographic resolution of rac-4-methyloctane and assign-for the first time - the absolute stereochemical configuration to the two baseline separated enantiomers. Figure 3 shows chromatograms of the individual enantiomers (top) and a chromatogram of the baseline resolved rac-4-methyloctane (bottom). Comparison with the individually injected enantiomers allows us to assign that the first eluting enantiomer is $(R)-4$-methyloctane and the second eluting enantiomers is (S)-4-methyloctane. On this $25 \mathrm{~m}$ column the gas chromatographic resolution Rs has been calculated to be 1.63 , which is above the often-used value of 1.5 for baseline separation, defined as $99 \%$ baseline resolution or less than $1 \%$ overlap between the 2 gaussian peaks. Compound identifications were done by comparison with the NIST mass spectral library and are detailed in Figure 4.

Based on this study, systematic investigations will follow to determine the absolute configuration of other chromatographically resolved hydrocarbon enantiomers such as homologues of 3-, 4-, and 5-methyl alkanes as well as chiral polymethylated hydrocarbons such as 2,3-dimethylheptane, 2,2,4-trimethylhexane and their homologues.

This is of high interest because the inclusion process of cyclodextrin stationary phases is complex and yet the elusive correlation of the absolute configuration of chiral alkanes with their gas-chromatographic elution order on these columns is of high relevance for research on enantiorecognition solely based on van der Waals forces [2,31]. $\beta$-cyclodextrins are made of 7 glucose units, and the internal diameter of the cavity formed by these units is only of about $6 \AA$ for a volume of $0.35 \mathrm{~nm}^{3}$. Therefore, one could expect that for larger molecules such as the 19- and 20-carbon isoprenoid alkanes-pristane and phytane put forward here, the inclusion process of cyclodextrins would be negligible and not result in great separation power. However molecular size does not appear to be a crucial factor [38], as chiral recognition is also determined outside of the cavity [39]. In fact, the two biological phytane epimers of $R, R, R$ and $R, R, S$ absolute configuration (Figure 1e) have already been separated on several cyclodextrin stationary phases [40], although not on the one used for this research and on board the ExoMars rover. Since only these two epimers out of the total eight stereoisomers of phytane are of biological descent, it would be of interest to analyze an all-racemic mixture of phytane and identify the different elution orders and behaviors of all stereoisomers on the CP Chirasil-Dex CB column of Agilent.

For pristane, the separation and analysis should be much simpler as biological pristane is of the meso form $R, S$ (see Figure 1d) and is a diastereoisomer of its abiotic enantiomeric forms $R, R$ and $S, S$. Therefore, only a separation between meso-pristane and its two abiological enantiomers is necessary to trace its origin, and this can and has been carried out on achiral capillary columns for sediments and crude oil analyses [27,29], but also marine samples such as shark liver oils [41]. We hope that the results presented here on the resolution of enantiomers of branched hydrocarbons will trigger future investigations on the separation of isoprenoid enantiomers that have not been achieved, so far. 


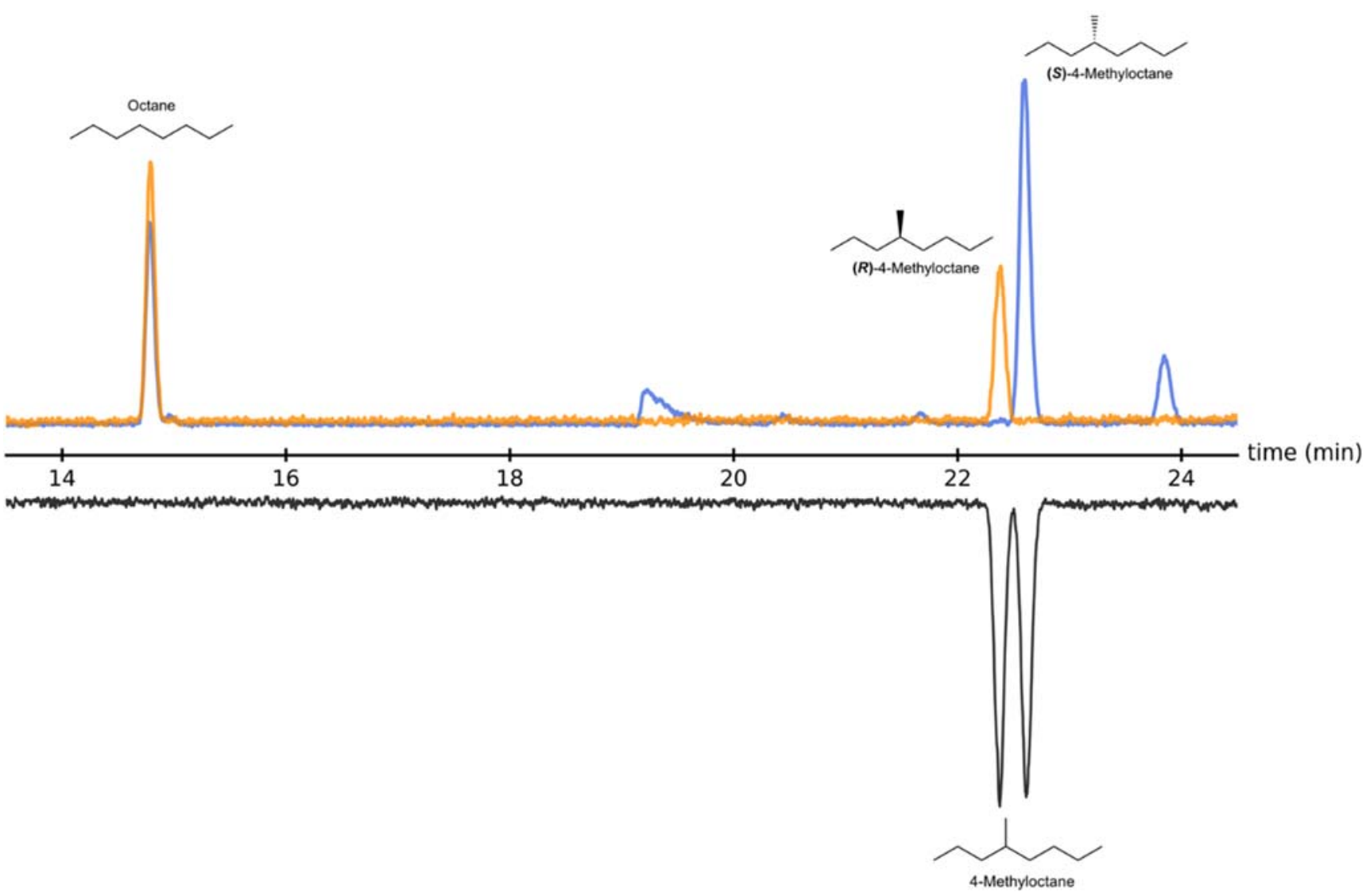

Figure 3. In black and upside-down the chromatogram of commercial rac-4-methyloctane, showing the baseline separated enantiomers; in orange and blue are, respectively, the chromatograms of synthesized pure $R$ and $S$ enantiomers of 4-methyloctane. Octane is seen in both as a synthetic by-product, as well as a few other minor impurities in the case of the $S$ enantiomer (1-butanol and 1-iodobutane at around 19.5 and $24 \mathrm{~min}$, respectively). The chromatograms of the pure enantiomers show perfect correspondence in retention time with each peak of rac-4-methyloctane, allowing for the clear association of the enantiomers with the signals from the racemic mixture. The identification of all compounds was carried out by mass spectral comparison with the NIST mass spectra database (Figure 4).
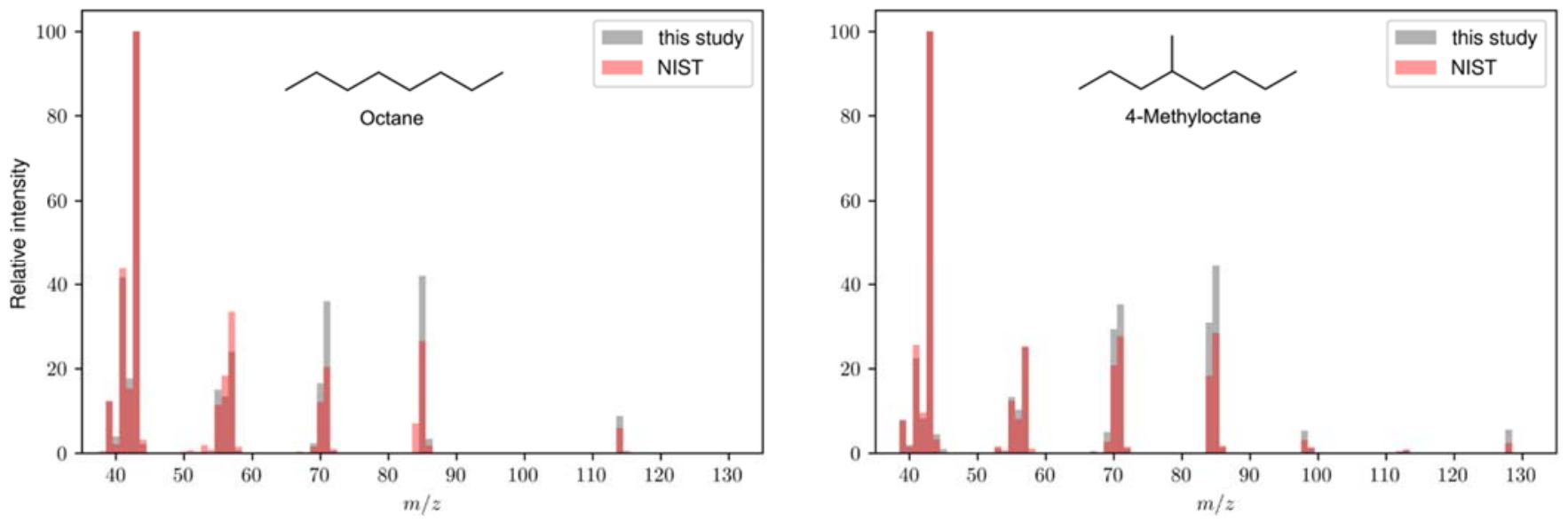

Figure 4. Comparison of the mass spectra of octane (left) and 4-methyloctane (right) from our analysis with the ones from the NIST database. The mass spectra of $(R)$ - and (S)-4-methyloctane are of course identical. We note a slightly increased sensitivity to higher masses on our mass spectrometer, but the compounds are clearly identified. 


\section{Discussion}

\subsection{Hydrocarbon Enantiomers in Biology}

Life on Earth is based on carbon chemistry operating in an aqueous environment. All living organisms have lipid membranes that are the interfaces between intercellular and extracellular environments. Lipid membranes allow for the formation of vesicles and thereby define the boundary between life and non-life [42].

Archaea and bacteria, chronologically the first two of the three domains of life, differ significantly in the hydrocarbon composition of their lipid membrane: in archaea, these are isoprenoid ether-linked to a glycerol unit (archaeol: Figure 1a), while in bacteria (and eukarya) they are ester-linked fatty acids [43]. This has led to questions about the membrane composition of the last universal common ancestor (LUCA) to understand the reasons why the membranes of archaea and bacteria diverged in the first place [44]. Research suggests that LUCA may have had both bacterial and archaeal membrane lipids [45], which would mean that the very first life forms on Earth presented in part an enantiomerically pure isoprenoid membrane [46]. Moreover, while bacteria fatty acid composition is subject to high variance between and even within species [47], archaeal membrane lipids seem to have typical phytanyl chains [48]. This is of immense interest for us as this would represent a first and significant source of pristane and phytane.

Later, photosynthetic bacteria evolved and used the essential chlorophyll pigments (Figure 1b). Most chlorophylls, including those used by cyanobacteria and most plants and algae possess a phytol side chain showing the same stereochemistry as the phytanyl chains of archaeol. Due to the abundance of photosynthetic organisms on Earth, the bulk of pristane and phytane is believed to be derived from the ester-linked phytol side chain of chlorophyll [26], after its release from hydrolysis of chlorophyll $a, b, d$ and $f$ during diagenesis in marine sediments. Phytoplankton is believed to be a major contributor of chlorophyll [49]. At the bottom of the marine food chain, phytoplanktonic phytol is catabolized by zooplankton [17] and hence found in higher marine organisms in the same enantiomerically pure form [41].

Tocopherols also possess a phytyl tail of the same stereochemistry (Figure 1c) and have been proposed as another likely precursor of pristane in ancient sediments and crude oils. Although one or two orders of magnitude less so than chlorophyll [50], they are relatively abundant in most photosynthetic organisms such as higher plants, algae, and cyanobacteria. Many bacteria have been reported to contain tocopherol derivatives [51]. Interestingly, while pristane is readily formed from tocopherols, the generation of phytane from this source is less likely because $\alpha$-cleavage next to the aromatic moiety is highly unfavorable [8].

It is interesting to note that while in the biomolecule the active part linked to the phytyl/phytanyl side chain makes the absolute configuration of the two outermost chiral carbons $R, R$, but when separated the resulting pristane is of $R, S$ configuration owing to the notational system's sequence rules, and becomes meso-pristane due to its internal plane of symmetry (Figure 1d).

Coming mainly from the diagenesis of the three families of biomolecules we just discussed, pristane and phytane are omnipresent in crude oils, coals, and ancient sediments [52]. The fact that in all these biomolecules, the isoprenoid side chain has the same absolute configuration (Figure 1), appears to show that the enzyme(s) involved in the reduction of the double bonds in the isoprenoid precursors of the archaeol phytanyl groups has the same stereospecificity as corresponding enzymes in photosynthetic organisms [9].

This stereospecificity has been used in geochemistry to obtain information on the origin and maturation of different sediments and petroleum through the level of isomerization of pristane and phytane in the samples [25-29]. Complete racemization of biological pristane was observed for a 300-million-year-old shale and a 50-million-year-old crude oil [17], highlighting the environment-dependent loss of stereospecificity. 


\subsection{Lifetime of "Molecular Fossiles"}

The stability of any candidates for "molecular fossils" should be discussed. The relative stability of carbohydrates, amino acids, carotenoids, porphyrins, and hydrocarbons increases in that order. For hydrocarbons, we have experimental evidence $\left(\Delta \mathrm{H}_{\mathrm{C}}=66.5 \mathrm{~kJ} / \mathrm{mol}\right.$, $\mathrm{A}=10^{14}$ ) for the breaking of a carbon-carbon single bond. The mean lifetime of a $\mathrm{C}-\mathrm{C}$ bond is then $10^{14.5}$ years at $400 \mathrm{~K}$ and $10^{27}$ years at $300 \mathrm{~K}$. For the dissociation by breaking off a pair of hydrogen atoms, using $\Delta \mathrm{H}_{\mathrm{H}}=63.0 \mathrm{~kJ} / \mathrm{mol}$ and $\mathrm{A}=10^{13}$ we can determine the mean lifetime as $10^{15.5}$ years at $400 \mathrm{~K}$ and $10^{25}$ years at $300 \mathrm{~K}$ [14]. Hydrocarbons are the most stable group of compounds and are expected to retain, even over geological timescales, a significant part of their original molecular structure. These calculations should also be valid for the stability of chiral hydrocarbons against racemization, which is expected to occur mainly via hydrogen subtractions [53]. However further systematic investigations are needed to understand pathways and kinetics of racemization reactions of chiral hydrocarbons in detail.

Although reported racemization times for shales and crude oils are much smaller than the theoretical calculations, we must not forget that they are in a very energetic environment compared to what we expect Mars' subsurface to be. In the very cold and a priori lifeless first meters of Martian sediments, protected from ionizing radiations, the isomerization timescales of hydrocarbons should be much closer to theoretical values that are well above our solar system's lifetime.

\subsection{Extraterrestrial Biology}

ExoMars has been designed to look for carbon-based life using water as a solvent: the only life form we know of. The landing site of the rover, Oxia Planum, was chosen for this purpose [13].

Under the hypothesis that lipids are required for carbon-based life forms, enantiomeric separation of hydrocarbons is of great importance. Life exploits the specificity inherent to the three-dimensional qualities of organic chemicals (stereochemistry). These characteristics then lead to some identifiable and measurable generic attributes that would be indicative as biosignatures. Those include enantiomeric excesses and diastereoisomeric preferences in any molecular family [24]. Homochirality is often correlated with biologic processes.

Chiral hydrocarbons are in principle the most adequate family of molecules to probe for extinct life elsewhere due to their notable stability as molecular fossils and their presence in the very first cell membranes that are necessary to all organisms we know of. We are then looking for remnants of life at its very beginning, maximizing the odds for its similarity with Earth's primitive organisms. The stereochemistry of chiral hydrocarbons should therefore be, on their own, one of the strongest hints at a biological or abiological source for a given sample.

Isoprenoids appear to have properties that are well suited to the rather harsh environments in which the archaea live [54]. They have been shown to improve the stability of membranes in the presence of salts but require concentrations 30 -fold higher for membrane formation [55]. Under different environmental conditions, other chiral hydrocarbons may be favored to be incorporated as the hydrophobic tail of cell membrane lipids.

In photosynthetic organisms, the phytol hydrocarbon tail of chlorophyll $a$ (Figure 1b) has the purpose of anchoring the molecule within a membrane and could therefore not be specific to Earth. As the environmental histories of Earth and Mars have diverged radically after the first few hundred million years, so would the history of any life on them. Still, possible life forms on Mars would be chemoautotrophic cryophiles adapted to a nutrient-poor environment or photoautotrophic organisms in selected near-surface habitats [56], making photosynthetic pigment remnants a real possibility.

Isoprenoid alkanes such as phytane, pristane, and norpristane have also been found in carbonaceous meteorites [57]. This was problematic and strongly hinted at a terrestrial contamination, but further analysis confirmed their presence as well as that of free heavy $n$-alkanes in some of the meteorites [58]. This could be (part of) an explanation for why 
they were used in biology by the first life forms, and an argument for very similar lipid membranes to have evolved on Mars. The lighter hydrocarbons, such as 4-methyloctane here, were not found and were hypothesized to slowly evaporate in space. Detection of these lighter hydrocarbons in Martian sediments would therefore have a different implication for their origin if they were found in conjunction with isoprenoids or not and vice versa. The fact that meteorite impacts can supply these isoprenoids (assuming they are in a racemic mixture then) is an additional reason for determining their stereochemistry if they are to be found on Mars. A racemic mixture could not, on its own, be disambiguated from meteoritic contribution. The additional information of their stereochemistry would be of great scientific value.

\subsection{The Chirality Part of ExoMars}

The MOMA instrument on board the Rosalind Franklin rover of the ESA's ExoMars mission is a gas chromatograph linked to a mass spectrometer (GC-MS) and has among its analytic tools the chiral capillary column CP Chirasil-Dex CB from Agilent [21]. The rover will be equipped with a drill to collect subsurface material from outcrops at depths down to $2 \mathrm{~m}$ and a distribution system for sample investigation by MOMA and other analytical instruments. These subsurface sampling capabilities will provide the best opportunity yet to gain access to chemical biosignatures [13].

It is straightforward to include-as proposed here-branched hydrocarbons in the chiral analytes of specific interest for the ExoMars mission. The classically targeted chiral analytes in form of amino acids and sugar units racemize and degrade much faster on geological timescales in comparison to the more stable and inert chiral hydrocarbons.

Results will open experimental opportunities to systematically synthesize, resolve, and assign the absolute configurations of hydrocarbon enantiomers.

The results further show that the chiral stationary phase selected for the ExoMars mission, the permethylated $\beta$-cyclodextrin Chirasil-Dex CB, is capable of resolving enantiomers of branched chiral hydrocarbons as presented here in the example of 4-methyloctane. The required gas chromatographic conditions are known and will-hopefully-allow us to investigate the chirality of branched hydrocarbons in surface and subsurface samples of Mars. Propane and several chloroalkanes, including chiral ones, have been detected by the Sample Analysis at Mars (SAM) instrument onboard NASA's Curiosity rover in surface samples of Mars [59]. Chiral hydrocarbons have not yet been identified on Mars.

The $20 \mathrm{~m}$ CP-Chirasil-Dex CB Agilent column on board of MOMA has been shown to allow the detection of $n$-alkanes up to heneicosane (C-21) within a nominal GC-MS run time and temperature program [22], in which the oven temperature goes up to $180{ }^{\circ} \mathrm{C}$ but not above to maintain the chiral stationary phase integrity. The branched 19- and 20-carbon pristane and phytane with a 15- and 16-carbon main chain, respectively, will then be well within the chromatographic space of this column. The three other capillary columns on board the MOMA instrument are the MXT-5, MXT-CLP and MXT Q BOND, all achiral and $20 \mathrm{~m}$ long [21]. Overall, they all show lower retention capabilities and higher maximum oven temperature tolerance compared to the Chirasil-Dex column, allowing for the detection of much larger molecules.

As previously pointed out, meso-pristane and biologically derived phytane should be separable from their abiological diastereoisomers even on these achiral columns. It would therefore be of great interest to inject an all-racemic mixture of these compounds on the flight spare MXT columns in addition to the Chirasil-Dex to evaluate the different separation power and the orders of elution of these isoprenoid stereoisomers. These results could be of the utmost importance if any of them were to be found in the gas chromatographic analyses that will be made on Mars. While the sole detection of pristane/phytane or deviations from an overall decreasing abundance with increasing carbon number of alkanes, such as even/odd carbon chain length imbalance or clumping at seemingly peculiar carbon numbers would already hint at a biological source $[13,14]$, the here-proposed additional information of stereochemistry identification on chiral hydrocarbons would 
provide exceptional weight to the claim of a biological origin. However, this requires laboratory calibrations to catalogue the feasibility and order of the stereoisomeric separation for all compounds of interest.

A short list of candidate hydrocarbons for the MOMA instrument onboard ExoMars rover are depicted in Figure 5. A more complete list of the acyclic isoprenoids appearing in biology can be found in the literature $[18,60]$. For achiral norfarnesane, no enantiomers are possible. For farnesane and norpristane, 4 stereoisomers $(R, S-, S, R-, S, S-, R, R-)$ are distinguishable. Pristane shows three stereoisomers $(S, S-, R, R-$, and meso-) and phytane shows eight stereoisomers, because of its additional third asymmetric center. The data presented here are intended to attract novel astrophysical interest to investigate chiral hydrocarbons on Mars. For this goal, systematic investigations on isoprenoid and chiral hydrocarbon enantiomer resolution and assignment of the absolute configuration are required and need to be performed in the near future.
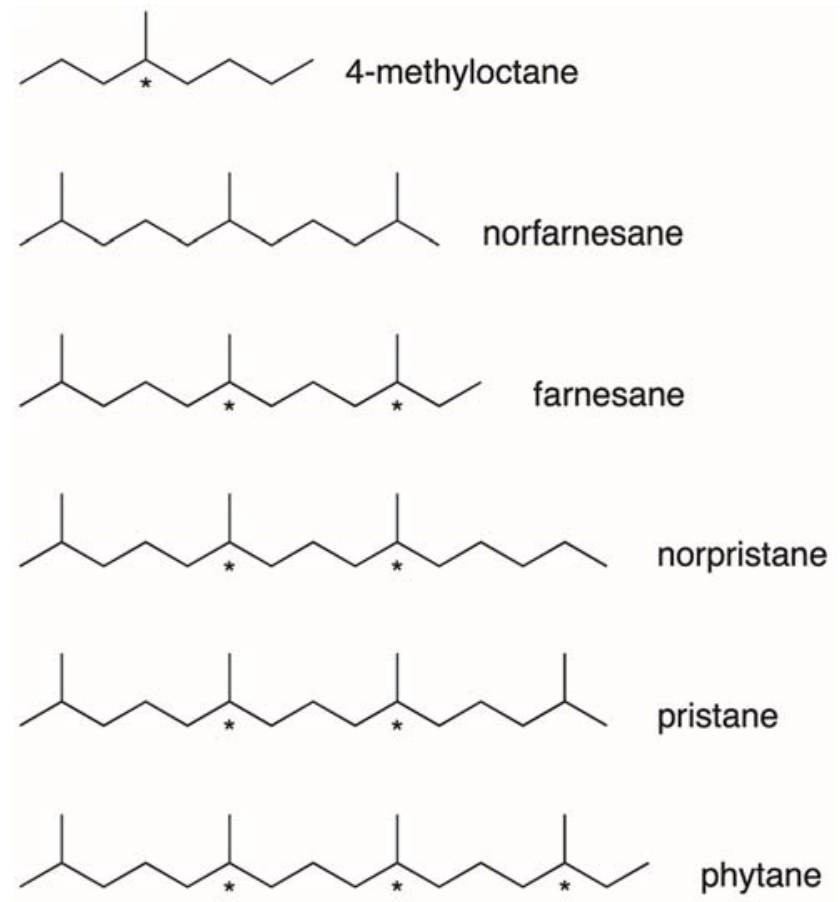

Figure 5. Some hydrocarbon analytes of interest for the ExoMars mission including 4-methyloctane, and the isoprenoids norfarnesane, farnesane, norpristane, pristane, and phytane. Asterisks show chiral centers.

\section{Conclusions}

The two enantiomers of 4-methyloctane were baseline separated and their absolute configuration was assigned for the first time. We show that on the CP-Chirasil-Dex CB column, consisting of $\beta$-cyclodextrin directly bonded to dimethylpolysiloxane, the $S$ enantiomer shows higher interaction with the chiral stationary phase and therefore higher retention time. While 4-methyloctane is not an isoprenoid alkane, it is one of the simplest chiral hydrocarbons and is therefore a starting point for future enantiomeric and diastereoisomeric separations and absolute configuration assignments.

Although pristane and phytane have usually been the most researched compounds in petrochemistry, other isoprenoids (acyclic and cyclic) could be of interest. Indeed, pristane and phytane are more resistant to biodegradation than $n$-alkanes, but less so than steranes and hopanes [42]. This introductive research hopes to bring about future systematic enantiomers elution order determination of hydrocarbons on these chiral columns.

The ESA's ExoMars mission contains the multicolumn gas chromatographic instrument Mars Organic Molecule Analyser (MOMA) for the separation and identification of 
organic molecules in surface and subsurface samples of Mars after landing at Oxia Planum in 2023. The MOMA module is equipped with a total of four capillaries with four different stationary phases. One of those phases is the enantioselective Chirasil-Dex CB phase using permethylated $\beta$-cyclodextrin. This enantioselective phase should not exclusively be used for the analysis of amino acid and sugar units, but also for the enantioselective analysis of chiral branched hydrocarbons. The in situ detection of the life-derived stereoisomers of chiral hydrocarbons on Mars will help to distinguish between their biological versus abiological origin. If homochirality or significant enantiomeric excesses of the presented branched hydrocarbon structures are to be identified by the Rosalind Franklin rover of the ExoMars mission in Mars samples in 2023, this result can be used as an important clue for the presence of ancient Earth-like life on Mars. These are some the most stable organic molecules, known to have been part of the very first life forms on Earth billions of years ago, and should therefore be some of our best molecular probes to explore the habitability of a young Mars.

Author Contributions: Conceptualization, J.-J.F. and U.M.; methodology, G.L., J.-J.F. and U.M.; chromatographic analyses, G.L., J.-J.F. and U.M.; chemical syntheses, N.B.; writing-original draft preparation, G.L.; writing-review and editing, U.M.; visualization, G.L.; supervision, U.M.; project administration, U.M.; funding acquisition, U.M. All authors have read and agreed to the published version of the manuscript.

Funding: This research was funded by ANR for funding UCAJEDI ANR-15-IDEX-01, ANR-16-CE290015, and ANR-18-CE29-004.

Acknowledgments: We thank the ESA and the MOMA Science Team for the realization of ExoMars and related discussions.

Conflicts of Interest: The authors declare no conflict of interest. The funders had no role in the design of the study; in the collection, analyses, or interpretation of data; in the writing of the manuscript, or in the decision to publish the results.

\section{References}

1. Meierhenrich, U.J.; Nguyen, M.-J.; Barbier, B.; Brack, A.; Thiemann, W.H.-P. Gas chromatographic separation of saturated aliphatic hydrocarbon enantiomers on permethylated cyclodextrin. Chirality 2003, 15, S13-S16. [CrossRef]

2. Sicoli, G.; Kreidler, D.; Czesla, H.; Hopf, H.; Schurig, V. Gas chromatographic enantioseparation of unfunctionalized chiral alkanes: A challenge in separation science (overview, state of the art, and perspectives). Chirality 2009, 21, 183-198. [CrossRef]

3. Saito, F.; Schreiner, P.R. Determination of the Absolute Configurations of Chiral Alkanes-An Analysis of the Available Tools. Eur. J. Org. Chem. 2020, 2020, 6328-6339. [CrossRef]

4. Nissenbaum, A.; Baedecker, M.J.; Kaplan, I.R. Organic geochemistry of Dead Sea sediments. Geochim. Cosmochim. Acta 1972, 36, 709-727. [CrossRef]

5. Rowland, S.J. Production of acyclic isoprenoid hydrocarbons by laboratory maturation of methanogenic bacteria. Org. Geochem. 1990, 15, 9-16. [CrossRef]

6. Rontani, J.-F.; Bonin, P. Production of pristane and phytane in the marine environment: Role of prokaryotes. Res. Microbiol. 2011, 162, 923-933. [CrossRef]

7. Dawson, D.; Grice, K.; Alexander, R.; Edwards, D. The effect of source and maturity on the stable isotopic compositions of individual hydrocarbons in sediments and crude oils from the Vulcan Sub-basin, Timor Sea, Northern Australia. Org. Geochem. 2007, 38, 1015-1038. [CrossRef]

8. Goossens, H.; de Leeuw, J.W.; Schenck, P.A.; Brassell, S.C. Tocopherols as likely precursors of pristane in ancient sediments and crude oils. Nature 1984, 312, 440-442. [CrossRef]

9. Kates, M.; Joo, C.N.; Palameta, B.; Shier, T. Absolute Stereochemical Configuration of Phytanyl (Dihydrophytyl) Groups in Lipids of Halobacterium cutirubrum. Biochemistry 1967, 6, 3329-3338. [CrossRef]

10. Meierhenrich, U.J. Amino Acids and the Asymmetry of Life: Caught in the Act of Formation; Springer: Berlin/Heidelberg, Germany, 2008.

11. Bada, J.L.; McDonald, G.D. Amino Acid Racemization on Mars: Implications for the Preservation of Biomolecules from an Extinct Martian Biota. Icarus 1995, 114, 139-143. [CrossRef]

12. Bada, J.L.; Wang, X.S.; Hamilton, H. Preservation of key biomolecules in the fossil record: Current knowledge and future challenges. Philos. Trans. R. Soc. London. Ser. B Biol. Sci. 1999, 354, 77-87. [CrossRef]

13. Vago, J.L.; Westall, F.; Pasteur Instrument Teams, L.S.; Coates, A.J.; Jaumann, R.; Korablev, O.; Ciarletti, V.; Mitrofanov, I.; Josset, J.-L.; De Sanctis, M.C.; et al. Habitability on Early Mars and the Search for Biosignatures with the ExoMars Rover. Astrobiology 2017, 17, 471-510. [CrossRef] 
14. Calvin, M. Chemical evolution. Chem. Br. 1969, 5, 22-28.

15. Harold, A. Illich Pristane, Phytane, and Lower Molecular Weight Isoprenoid Distributions in Oils. Am. Assoc. Pet. Geol. Bull. 1983, 67, 385-393. [CrossRef]

16. Mackenzie, A.S. Applications of Biological Markers in Petroleum Geochemistry. In Advances in Petroleum Geochemistry; Elsevier: Amsterdam, The Netherlands, 1984; Volume 1, pp. 115-214. ISBN 0120320010.

17. Patience, R.L.; Rowland, S.J.; Maxwell, J.R. The effect of maturation on the configuration of pristane in sediments and petroleum. Geochim. Cosmochim. Acta 1978, 42, 1871-1875. [CrossRef]

18. Gassmann, G. Chromatographic separation of diasteriomeric isoprenoids for the identification of fossil oil contamination. Mar. Pollut. Bull. 1981, 12, 78-84. [CrossRef]

19. van Graas, G.; de Leeuw, J.W.; Schenck, P.A.; Haverkamp, J. Kerogen of Toarcian shales of the Paris Basin. A study of its maturation by flash pyrolysis techniques. Geochim. Cosmochim. Acta 1981, 45, 2465-2474. [CrossRef]

20. Summons, R.E. The Exceptional Preservation of Interesting and Informative Biomolecules. Paleontol. Soc. Pap. 2014, 20, 217-236. [CrossRef]

21. Goesmann, F.; Brinckerhoff, W.B.; Raulin, F.; Goetz, W.; Danell, R.M.; Getty, S.A.; Siljeström, S.; Mißbach, H.; Steininger, H.; Arevalo, R.D.; et al. The Mars Organic Molecule Analyzer (MOMA) Instrument: Characterization of Organic Material in Martian Sediments. Astrobiology 2017, 17, 655-685. [CrossRef]

22. Guzman, M.; Szopa, C.; Freissinet, C.; Buch, A.; Stalport, F.; Kaplan, D.; Raulin, F. Testing the capabilities of the Mars Organic Molecule Analyser (MOMA) chromatographic columns for the separation of organic compounds on Mars. Planet. Space Sci. 2020, 186, 104903. [CrossRef]

23. Reinhardt, M.; Goetz, W.; Thiel, V. Testing Flight-like Pyrolysis Gas Chromatography-Mass Spectrometry as Performed by the Mars Organic Molecule Analyzer Onboard the ExoMars 2020 Rover on Oxia Planum Analog Samples. Astrobiology 2020, 20, 415-428. [CrossRef]

24. Summons, R.E.; Albrecht, P.; McDonald, G.D.; Moldowan, J.M. Molecular Biosignatures. Space Sci. Rev. 2008, 135, 133-159. [CrossRef]

25. Wu, Y.; Xia, Y.; Wang, Y.; Lei, T.; Liu, Y.; Liu, Y.; Hou, X.; Wang, Y. The Geochemical Characteristics of Coals from the Junggar Basin in Northwest China and the Relation of the Configuration of Pristane with Maturity in Highly Mature and Over-Mature Samples. Oil Gas Sci. Technol. Rev. D'ifp Energ. Nouv. 2016, 71, 35. [CrossRef]

26. Maxwell, J.R.; Cox, R.E.; Eglinton, G.; Pillinger, C.T.; Ackman, R.G.; Hooper, S.N. Stereochemical studies of acyclic isoprenoid compounds-II The role of chlorophyll in the derivation of isoprenoid-type acids in a lacustrine sediment. Geochim. Cosmochim. Acta 1973, 37, 297-313. [CrossRef]

27. Püttmann, W.; Eckardt, C.B. Influence of an intrusion on the extent of isomerism in acyclic isoprenoids in the Permian Kupferschiefer of the Lower Rhine Basin, N.W. Germany. Org. Geochem. 1989, 14, 651-658. [CrossRef]

28. Patience, R.L.; Yon, D.A.; Ryback, G.; Maxwell, J.R. Acyclic isoprenoid alkanes and geochemical maturation. Phys. Chem. Earth 1980, 12, 287-293. [CrossRef]

29. McIntyre, C.P.; Harvey, P.M.; Ferguson, S.H.; Wressnig, A.M.; Volk, H.; George, S.C.; Snape, I. Determining the Extent of Biodegradation of Fuels Using the Diastereomers of Acyclic Isoprenoids. Environ. Sci. Technol. 2007, 41, 2452-2458. [CrossRef]

30. Armstrong, D.W.; Tang, Y.; Zukowski, J. Resolution of enantiomeric hydrocarbon biomarkers of geochemical importance. Anal. Chem. 1991, 63, 2858-2861. [CrossRef]

31. Schurig, V.; Kreidler, D. Gas-Chromatographic Enantioseparation of Unfunctionalized Chiral Hydrocarbons: An Overview. Methods Mol. Biol. 2013, 970, 45-67, ISBN 9781627032629.

32. Meierhenrich, U.J.; Thiemann, W.H.-P.; Rosenbauer, H. Molecular parity violation via comets? Chirality $1999,11,575-582$. [CrossRef]

33. Meierhenrich, U.J. Comets and Their Origin; Meierhenrich, U., Ed.; Wiley-VCH Verlag GmbH \& Co. KGaA: Weinheim, Germany, 2014; ISBN 9783527412778.

34. Meierhenrich, U.J.; Thiemann, W.H.-P.; Goesmann, F.; Roll, R.; Rosenbauer, H. Enantiomer separation of hydrocarbons in preparation for ROSETTA's chirality-experiment. Chirality 2001, 13, 454-457. [CrossRef]

35. König, W.A.; Icheln, D.; Runge, T.; Pforr, I.; Krebs, A. Cyclodextrins as chiral stationary phases in capillary gas chromatography. Part VII: Cyclodextrins with an inverse substitution pattern-synthesis and enantioselectivity. J. High Resolut. Chromatogr. 1990, 13, 702-707. [CrossRef]

36. Freissinet, C.; Buch, A.; Szopa, C.; Sternberg, R. Enantiomeric separation of volatile organics by gas chromatography for the in situ analysis of extraterrestrial materials: Kinetics and thermodynamics investigation of various chiral stationary phases. J. Chromatogr. A 2013, 1306, 59-71. [CrossRef]

37. Johnson, C.R.; Dutra, G.A. Reactions of lithium diorganocuprates(I) with tosylates. II. Stereochemical, kinetic, and mechanistic aspects. J. Am. Chem. Soc. 1973, 95, 7783-7788. [CrossRef]

38. Schurig, V.; Nowotny, H.-P. Gas Chromatographic Separation of Enantiomers on Cyclodextrin Derivatives. Angew. Chem. Int. Ed. Engl. 1990, 29, 939-957. [CrossRef]

39. Sicoli, G.; Jiang, Z.; Jicsinsky, L.; Schurig, V. Modified Linear Dextrins ("Acyclodextrins") as New Chiral Selectors for the Gas-Chromatographic Separation of Enantiomers. Angew. Chem. Int. Ed. 2005, 44, 4092-4095. [CrossRef] 
40. Huang, K.; Armstrong, D.W. GC-MS analysis of crocetane, phytane and some of their stereoisomers using cyclodextrin-based stationary phases. Org. Geochem. 2009, 40, 283-286. [CrossRef]

41. Cox, R.E.; Maxwell, J.R.; Ackman, R.G.; Hooper, S.N. Stereochemical Studies of Acyclic Isoprenoid Compounds. III. The Stereochemistry of Naturally Occurring (Marine) 2,6,10,14-Tetramethylpentadecane. Can. J. Biochem. 1972, 50, $1238-1241$. [CrossRef]

42. Peters, K.E.; Walters, C.C.; Moldowan, J.M. The Biomarker Guide; Cambridge University Press: Cambridge, MA, USA, 2004; ISBN 9780521781589.

43. Koga, Y. Thermal Adaptation of the Archaeal and Bacterial Lipid Membranes. Archaea 2012, 2012, 1-6. [CrossRef]

44. Matsumi, R.; Atomi, H.; Driessen, A.J.M.; van der Oost, J. Isoprenoid biosynthesis in Archaea-Biochemical and evolutionary implications. Res. Microbiol. 2011, 162, 39-52. [CrossRef] [PubMed]

45. Koga, Y. Early Evolution of Membrane Lipids: How did the Lipid Divide Occur? J. Mol. Evol. 2011, 72, 274-282. [CrossRef]

46. Wächtershäuser, G. From pre-cells to Eukarya-A tale of two lipids. Mol. Microbiol. 2003, 47, 13-22. [CrossRef] [PubMed]

47. Sohlenkamp, C.; Geiger, O. Bacterial membrane lipids: Diversity in structures and pathways. FEMS Microbiol. Rev. 2016, 40, 133-159. [CrossRef] [PubMed]

48. Woese, C.R.; Magrum, L.J.; Fox, G.E. Archaebacteria. J. Mol. Evol. 1978, 11, 245-252. [CrossRef] [PubMed]

49. Rontani, J.-F.; Volkman, J.K. Phytol degradation products as biogeochemical tracers in aquatic environments. Org. Geochem. 2003, 34, 1-35. [CrossRef]

50. Bucke, C.; Leech, R.M.; Hallaway, M.; Morton, R.A. The taxonomic distribution of plastoquinone and tocopherolquinone and their intracellular distribution in leaves of Vicia faba L. Biochim. Biophys. Acta Biophys. Incl. Photosynth. 1966, 112, 19-34. [CrossRef]

51. Hughes, P.E.; Tove, S.B. Occurrence of alpha-tocopherolquinone and alpha-tocopherolquinol in microorganisms. J. Bacteriol. 1982, 151, 1397-1402. [CrossRef] [PubMed]

52. Nip, M. Chemical Characterization of Coals, Coal Macerals and their Precursors: A Study by Analytical Pyrolysis; Technische Universiteit Delft: Delft, The Netherlands, 1987.

53. Meierhenrich, U.J.; Thiemann, W.H.-P.; Barbier, B.; Schubert, C.J.; Brack, A. Isoprenoid enantiomers as molecular biomarkers in ancient sediments. In Proceedings of the Geochemistry and the Origin of Life; Nakashima, S., Maruyama, S., Brack, A., Windley, B.F., Eds.; Universal Academy Press: Tokyo, Japan, 2001; pp. 269-284.

54. Kates, M. Biology of halophilic bacteria, Part II. Experientia 1993, 49, 1027-1036. [CrossRef]

55. Jordan, S.F.; Nee, E.; Lane, N. Isoprenoids enhance the stability of fatty acid membranes at the emergence of life potentially leading to an early lipid divide. Interface Focus 2019, 9, 20190067. [CrossRef]

56. Schulze-Makuch, D.; Irwin, L.N.; Lipps, J.H.; LeMone, D.; Dohm, J.M.; Fairén, A.G. Scenarios for the evolution of life on Mars. J. Geophys. Res. 2005, 110, E12S23. [CrossRef]

57. Cronin, J.R.; Pizzarello, S. Aliphatic hydrocarbons of the Murchison meteorite. Geochim. Cosmochim. Acta 1990, 54, 2859-2868 [CrossRef]

58. Kissin, Y.V. Hydrocarbon components in carbonaceous meteorites. Geochim. Cosmochim. Acta 2003, 67, 1723-1735. [CrossRef]

59. Freissinet, C.; Glavin, D.P.; Mahaffy, P.R.; Miller, K.E.; Eigenbrode, J.L.; Summons, R.E.; Brunner, A.E.; Buch, A.; Szopa, C.; Archer, P.D.; et al. Organic molecules in the Sheepbed Mudstone, Gale Crater, Mars. J. Geophys. Res. Planets 2015, 120, 495-514. [CrossRef]

60. Risatti, J.B.; Rowland, S.J.; Yon, D.A.; Maxwell, J.R. Stereochemical studies of acyclic isoprenoids-XII. Lipids of methanogenic bacteria and possible contributions to sediments. Org. Geochem. 1984, 6, 93-104. [CrossRef] 